\title{
Diversidade e diferenciação pela pesquisa universitária
}

\section{Célia Elizabete Caregnato*}

\section{Resumo}

Os sistemas nacionais de Ensino Superior são diversificados e complexos, o que cria condiçóes para a produção de pesquisa e de conhecimento pelas instituiçóes com variados graus de abrangência e de repercussão. O presente artigo registra a construção de um caminho para a análise da relação entre a diversidade institucional e a atividade de pesquisa. Ao se interpretar a diferenciação de características das instituiçóes de mesma natureza, contribui-se para o conhecimento do sistema de Ensino Superior. Recorre-se à metodologia de análise weberiana do tipo-ideal, sem, portanto, proporem-se modelos para classificar as instituiçóes reais ou os modelos ideais a serem atingidos.

Palavras-chave: Pesquisa educacional. Ensino Superior. Universidades e faculdades.

* Doutora em Educação pela Universidade Federal do Rio Grande do Sul (UFRGS) e docente adjunto da UFRGS. 
Os sistemas nacionais de Ensino Superior são diversificados e complexos, em decorrência de que a produção oriunda da atividade de pesquisa desenvolvida institucionalmente pode se apresentar com variados graus de abrangência e obter distintos níveis de repercussão. Instituiçóes com a mesma classificação legal apresentam diversidade, não apenas quanto a missões, mas também devido a concepçôes e à prevalência de algumas áreas em relação a outras. A atividade de pesquisa, apesar das intrincadas relações e dos diferenciados resultados que pode encerrar, constitui-se em um meio importante para o estudo da diversidade institucional. $\mathrm{O}$ presente artigo, com origem em uma pesquisa sobre o tema ${ }^{1}$, apresenta elementos para a análise da relação entre diversidade institucional e atividade de pesquisa. Trabalha com as noçóes de cosmopolitismo e regionalismo, que remetem a situaçóes extremas quando pensadas em termos de realidade.

No caso deste estudo, as noçóes de cosmopolitismo e regionalismo são constituídas com base no recurso ao tipo-ideal weberiano. De acordo com a construção weberiana, ambas são conceitos, portanto abstratos e sem assento na realidade como tal. Os tipos são criados para fins de análise, não se traduzem, pois, de forma direta na realidade, uma vez que esta sempre é mais densa e subjetiva, podendo inclusive mesclar elementos pontuais de diferentes tipos mentais, ou seja, traços daquilo que se categoriza como cosmopolitismo e regionalismo apresentam-se interligados numa mesma realidade. Como recurso analítico, de qualquer forma, os tipos ideais servem de instrumento para a interpretação, criando parâmetros para comparação com a realidade estudada, auxiliando a análise.

O estudo não tem como objetivo de avaliação a pretensa validade superior ou inferior das instituiçôes, mas visa à criação de meios para análise, cumprindo a finalidade de contribuir para o conhecimento do Ensino Superior brasileiro focalizado a partir de sua diversidade institucional e regional.

A construção dos modelos, então, não é uma classificação com a finalidade de enquadrar instituiçóes numa ou noutra categorização, não significa, também, hierarquia quanto à missão ou quanto ao significado para sua comunidade e/ ou região. Interpretam-se aspectos do tipo de competitividade exercido pela instituição e, embora a categorização se refira às instituiçóes, centra-se no desenvolvimento de áreas de conhecimento e da atividade de pesquisa no seu interior, a fim de relacioná-los com aspectos culturais das instituiçóes. Em última 
análise, o objetivo é verificar a tradução entre traços identitários das instituições e o conhecimento produzido em áreas eleitas.

Ressalta-se, ainda, a compreensão de que a diversidade e também a diferenciação são elementos concretos da dinâmica de desenvolvimento da realidade na vida em sociedade. Assim, mais do que debater com pretensão de julgamento sobre a variedade de características, cabe construir caminhos para reconhecê-las em sua variação, bem como para interpretar o papel que cumprem na vida social. O objetivo neste artigo é o estabelecimento de parâmetros para interpretação da questão do desenvolvimento de instituiçóes universitária, tendo a atividade de pesquisa como referência.

Antes de tratar diretamente da compreensão e da constituição dos tipos, abordam-se elementos de caracterização do Ensino Superior e das instituições universitárias que contribuem para situar a realidade focalizada.

\section{Aspectos da macrorrealidade}

Cabe registrar aspectos relativos ao desenvolvimento do Ensino Superior, especialmente privado ${ }^{2}$, tanto do ponto de vista histórico como do ponto da caracterização institucional, os quais permitem visualizar a heterogeneidade e a diversidade que lhe são intrínsecas.

Um primeiro aspecto diz respeito ao tempo histórico de consolidação das instituições. Ele é significativo, não só pela possibilidade de variação da maturidade, mas também pela verificação de que há tendências constituídas no processo de origem e no desenvolvimento do sistema nacional de Ensino Superior. Essa situação permite que se entendam elementos da organização acadêmico-administrativa e de mantença, as quais mantêm relação com a vida acadêmica nas Instituiçóes de Ensino Superior (IES).

Há variaçôes no surgimento de instituiçôes: nos anos 1940 e 50, surgem as confessionais; nos anos 1960 e 70 , as comunitárias e privadas, e nos anos 90, ocorre o surgimento de um chamado novo setor de instituiçóes privadas ou particulares. Assim, o processo de expansão do Ensino Superior no Brasil pode ser recortado em três fases, considerando-se características de mantenedoras das instituiçóes.

Nos anos 1950, as instituiçôes de Ensino Superior desenvolveram-se de forma importante por meio das universidades confessionais. O fato é que 
o limite na oferta de vagas neste período provocou mudanças significativas. Tais instituiçóes gozam de prestígio junto aos meios acadêmicos e não são entendidas como privadas em sentido estrito. Expandiram-se em tamanho e alcançaram maturidade acadêmica suficiente para estarem hoje mais próximas das universidades públicas de pesquisa.

Embora a Lei de Diretrizes e Bases da Educação Nacional (LDB) de 1961 admitisse que o sistema de Ensino Superior não mais deveria ser organizado preferencialmente por instituiçóes universitárias, é principalmente a partir da reforma de 1968 que ocorre a expansão de instituiçôes e de vagas no Ensino Superior. O perfil das instituições criadas era de caráter privado, não universitário e predominantemente objeto de iniciativa laica. O setor particular/privado do Ensino Superior brasileiro é dominante em termos quantitativos e cresce de modo bastante heterogêneo. O caminho construído pelas políticas estatais para a ampliação do acesso ao Ensino Superior no passado e no presente foi o da multiplicação de vagas nesse setor.

Decorrente da reforma de 1968, houve grande proliferação de IES não universitárias, mantidas por grupos laicos. Estas se expandiram como promotoras do Ensino Superior característico do ensino de massa, nas áreas de menor custo de investimentos - Ciências Humanas e Sociais -, com grande oferta de cursos noturnos para estudantes trabalhadores, sem fazerem investimento em atividades de pesquisa e extensão. $\mathrm{O}$ grande crescimento do setor privado entre o final dos anos de 1960 até meados dos anos $1970^{3}$ decorreu da flexibilização do modelo universitário e da consequente redução de custos possibilitada por essa flexibilização.

O crescimento do Ensino Superior privado foi limitado durante a década de 1980 e parte dos anos 1990. Entre as razóes para isso, computase o estrangulamento do Ensino Médio no País, que reduziu a demanda de concluintes e, consequentemente, de ingressantes do Ensino Superior, e o quadro econômico nacional da chamada "década perdida". Entretanto, nesse período houve também aglutinação de estabelecimentos.

Os principais fenômenos ligados às IES privadas, a partir dos anos 1980, segundo Sampaio (2000), foram a diminuição do número de estabelecimentos isolados, a desconcentração regional, a estabilidade e o declínio do número de matrículas do setor privado, aliados ao crescimento do número de cursos com ampliação das carreiras. Entre 1980 e 1994, o 
número de universidades privadas passou de 20 para 59, enquanto o número de instituiçóes isoladas passou de 643 para 490.

Na segunda metade dos anos 1990, ocorreu um novo e expressivo período de crescimento do setor. Dessa vez, houve uma política deliberada de estímulo ao setor privado para ampliação de vagas que facilitassem o acesso à escolarização superior. Com base na Lei de Diretrizes e Bases da Educação de 1996, os novos empreendedores no campo da Educação Superior passaram a expandir seu mercado, com base em mantenedoras e instituiçóes fundadas nas relaçóes de mercado em sentido estrito: poderiam visar ao lucro. Ocorreram intenso crescimento de vagas e agigantamento de instituiçôes. $\mathrm{O}$ fenômeno do não-preenchimento de vagas paralelo à baixa escolarização da população salta aos olhos.

Nos anos 2000, o fenômeno das fusóes de IES privadas e do aprofundamento do caráter acadêmico em algumas dessas instituiçóes ocorre paralelamente à grande expansão na oferta de vagas a preços competitivos, aliada à qualidade duvidosa da Educação Superior ofertada. Nunes (2007) mostra que, de qualquer maneira, o grande salto de expansão do setor privado ocorreu entre 1997 e 2005, período durante o qual muitos mantenedores transformaram o caráter de suas mantidas, adequando-as a categorias superiores, de acordo com a classificação originada da LDB/1996 (BRASIL, 2001). Estavam registradas, em março de 2007, 1.693 mantenedoras públicas e privadas, 93\% das quais são privadas (NUNES, 2007). Outro dado importante, oriundo do mesmo estudo (NUNES, 2007), é que, considerando-se a oferta de pelo menos três cursos de mestrado e um de doutorado, requisito presente entre segmentos que discutem o anteprojeto de Lei da Reforma da Educação Superior, constata-se que menos da metade do total de universidades brasileiras atende ao critério. Especificamente nas instituições privadas, a proporção de universidades que atendem à condição indicada é de 30\% (NUNES, 2007).

É preciso considerar o fato, ressaltado por Nunes, de que a universidade no Brasil é definida com base na lei ${ }^{4}$, e não no fundamento acadêmico. Há várias universidades sem programas de doutorado, contraditoriamente à concepção e ao fato de que é em programas de pós-graduação stricto sensu que ocorre profundamente a integração entre pesquisa e ensino. É importante registrar, ainda, que essa compreensão desvalorizadora do critério acadêmico não está presente apenas no setor privado, mas também na criação de 
universidades públicas que são instituídas desde uma condição embrionária, mas já com essa nomeação forçada de universidade.

De outra parte, Steiner (2005b) constrói uma classificação para instituiçóes de Ensino Superior, visando a interpretar o lugar ocupado pelas instituiçóes de acordo com o caráter acadêmico de suas atividades, especialmente focalizando o nível da pós-graduação stricto sensu. Com base nisso, é possível verificar que universidades e institutos públicos dominam o cenário das instituiçóes de doutorado e apenas elas compóem o grupo de Universidades consideradas de Pesquisa e Doutorado Diversificadas. ${ }^{5}$ Nenhuma possui referência internacional, o que caracterizaria um caráter cosmopolita mais acentuado. Por sua vez, as instituiçôes comunitárias/ confessionais/filantrópicas participam com certa expressividade entre as IES de doutorado e de mestrado. Não há instituições particulares de doutorado e elas também não aparecem entre as de mestrado de mais alta classificação.

De fato, as instituiçóes públicas e federais foram aquelas que tiveram oportunidade de desenvolver de forma expressiva a atividade de pesquisa a partir da Lei no 5.540/68 (BRASIL, 2010) e do impulso dado à pós-graduação stricto sensu. Esse fator foi propulsor da pós-graduação e contribui para compreender a qualidade aferida hoje. As IES confessionais desenvolveram-se, relativamente às particulares, em uma fase mais precoce da história do Ensino Superior. Outros fatores, entretanto, contribuem para a condição de desenvolvimento tardio das universidades não estatais como, por exemplo, o recente investimento em atividades de pesquisa.

Sabe-se da heterogeneidade do sistema de Ensino Superior brasileiro, que apresenta não só diversificação, mas também diferenças importantes entre instituiçóes com a mesma categoria acadêmica. De outra parte, parece oportuno justamente o estudo de casos, a fim de contribuir para a constituição de uma compreensão mais efetiva da realidade e dos desafios que precisam ser enfrentados. Genericamente, sabemos que as instituiçóes cujas mantenedoras são privadas se situam entre aquelas que mais têm a desenvolver no campo da pesquisa e da pós-graduação.

Quanto à diferenciação, oriunda da organização acadêmica administrativa, vê-se que não só as universidades, mas também institutos e centro tecnológicos de pesquisa colocam-se no ranking dos produtores de condiçóes para adquirir os status de grande competidores na área. No caso do sistema de Ensino Superior brasileiro, a diversificação institucional legal tem 
separado instituições de pesquisa e instituições de ensino. As universidades constituem o tipo que deve se dedicar à pesquisa, enquanto os centros universitários, as faculdades e os institutos não têm essa obrigatoriedade. Apesar disso, a diversidade que se constitui no desenvolvimento real das IES nem sempre confirma a classificação legal.

No quadro da realidade contraditória, veem-se instituiçôes classificadas de forma distintas como universidades e centros universitários, apresentando, em certos casos, poucas diferenças quanto ao trabalho acadêmico, e isso não é tâo incomum. ${ }^{6}$

Enfim, no que tange à macrorrealidade do Ensino Superior privado e de suas instituiçóes, de fato a heterogeneidade é grande, e isso oferece condiçóes para que se afirme a diversidade a partir de atuação, quem sabe acadêmica e administrativamente planejada para fins de desenvolvimento da pesquisa, do ensino e das instituições. A investigação empírica deve contribuir para o conhecimento dessa realidade, e o exercício intelectual de construção de tipos permite a organização de caminhos para a investigação.

\section{Os modelos ideais}

O termo "cosmopolita" remete à compreensão de que se trata de alguém ou alguma coisa "de quem a pátria é o mundo" (HOLANDA, 2006). As instituiçôes de Ensino Superior de caráter cosmopolita seriam capazes de responder à função da universidade na vida social e dariam conta de demandas de tempos de alto desenvolvimento científico, tecnológico e cultural.

A universidade como instituição de caráter específico é, por natureza, universalista, não só pelas áreas do conhecimento com as quais trabalha, mas também porque está na ponta ou na fronteira da produção de novos conhecimentos. Ela também tem a função especial de produzir criticamente, empenhando-se em interpretar e superar seus próprios limites, além daqueles da sociedade em que se insere. De fato, nem todas as universidades reais realizam plenamente as características que o título lhes confere, o que acarretaria exercerem as atividades e produzirem resultados de forma variada e complexa.

Além do caráter próprio da universidade, a instituição de Ensino Superior caracterizada como cosmopolita revelaria a capacidade de 
implementação de estudos e de debates de caráter internacional, de obtenção de alta produção e produtividade em pesquisa, de formação qualitativa e quantitativamente expressiva de pessoas em pós-graduação stricto sensu, bem como de oferta dos maiores títulos em uma importante diversidade de áreas. $\mathrm{Na}$ atividade de pesquisa, seria capaz de produzir repercussão de caráter internacional.

De outra parte, o termo regional diz respeito a agrupamentos por regiôes e a interesses por regiôes (HOLANDA, 2006). Uma instituição de Ensino Superior seria regional quando oriunda de interesses locais e, sendo assim, teria como função primordial o cuidado com esses interesses, podendo ou não dialogar com espaços e lógicas de maior abrangência, conforme sua capacidade. Esse tipo de instituição colocaria em foco a escolarização para o fornecimento de títulos em carreiras a serem desenvolvidas localmente e produziria interlocução com o mundo exterior na medida em que fosse do interesse para o desenvolvimento regional.

Como não se trata de buscar na realidade os tipos extremos, mas de identificar traços que sirvam como instrumento para conhecer, descobrir o real, por meio da atividade de pesquisa praticada na instituição, considerase que as instituiçôes de Ensino Superior podem estar localizadas na regiáo metropolitana e em regióes do interior, sendo esse um fator não diretamente determinante de sua caracterização. De fato, estar localizada na região metropolitana não significa necessariamente ser cosmopolita. Uma região, pela natureza das trocas e pelo acesso a fontes variadas de relaçóes sociais e culturais, pode evidenciar a presença de referenciais e interlocutores com tendência à expansão e ao diálogo para fora. Entretanto, isso só pode ser verificado no conjunto das características da instituição e no desenvolvimento de sua atividade de pesquisa e de pós-graduação.

Pensar em tipos-ideais é sempre pensar em tipos abstratos, que precisam ser construídos a partir de elementos da realidade, da interpretação e da seleçáo realizada no processo da pesquisa. Assim, cabe buscar aspectos gerais das noções eleitas como instrumento para o estudo.

\section{Cosmopolita}

Estudos recentes sobre o Ensino Superior contribuem para a formação da noção de cosmopolitismo, e, para tanto, vale buscar elementos da noção 
de "universidade de classe internacional". Para Schwartzman, as universidades de classe internacional (World Class Universities) (ALTBACH, 2003) são aquelas que

[...] devem desenvolver ciência e tecnologia, mas também cultura e formação geral, conhecimento e capacidade de entender o que ocorre no país e no mundo. Elas devem formar professores, diplomatas, altos funcionários, políticos, jornalistas, historiadores. Elas devem servir de ponte de contato e comunicação entre o país e o mundo, e servir de referência de qualidade e relevância para outras instituiçôes. (SCHWARTZMAN, 2004).

No campo da pesquisa, a universidade de classe internacional precisa ter qualidade reconhecida internacionalmente, precisa "ter liberdade de pesquisa de ensino e de comunicação", e autonomia acadêmica. Caracterizase por estar aberta a pessoas com diferentes origens culturais e requer altos valores para ser financiada, especialmente porque precisa disponibilizar infraestrutura para a pesquisa. Além disso, uma vez que "[...] não é possível substituir formação personalizada por tecnologia de qualquer tipo" (SCHWARTZMAN, 2004), a universidade de classe internacional utiliza tecnologia avançada e dedica-se, com infraestrutura e atenção, à formação de pessoas, o que contribui para o seu alto custo.

Uma universidade de classe internacional não pode ser endógena nem na produção nem na titulação dos docentes. Schwartzman (2006), analisando o caso da Universidade de São Paulo, chama a atenção para o fato de que nem mesmo essa grande universidade brasileira atende aos requisitos para ser classificada como universidade classe internacional, uma vez que apresenta traços de caráter endógeno na formação de seus quadros.

$\mathrm{O}$ autor afirma que a endogenia está fortemente presente em instituições paulistas. Refere-se especialmente ao lugar de obtenção dos títulos acadêmicos, registrando que cerca de $90 \%$ dos professores em universidade paulistas obtiveram seus diplomas em instituiçóes brasileiras. Ressalva o fato de que, naquela região, há tradição, e uma importante experiência e oferta de doutorados por instituiçóes tradicionais, fato que contribui para a endogenia. 
Efetivamente, não tem sido fácil para as instituições brasileiras obter resultados de estudos internacionais que as classifiquem como "de classe internacional" ou como cosmopolitas. Em geral, as instituiçóes que estão no topo dos sistemas são tradicionais e também atendem a um público restrito, especialmente naquelas áreas ou naquelas atividades em que se destacam. Disso decorre que universidades se destaquem em algumas áreas em detrimento de outras. De qualquer forma, a ideia de universidade de classe internacional traduz exigências bastante expressivas e classifica as instituições em grau de hierarquia superior no interior de um sistema nacional.

Conforme estudos de Steiner (2005a), que visam a estabelecer uma classificação para as instituiçôes de Ensino Superior brasileiras, baseada em estudos internacionais ${ }^{7}$, é mais produtivo classificar tendo como referencial a pós-graduação do que a atividade de pesquisa. Esta encerraria uma complexidade maior de elementos para aferição. Evidentemente, para fins de classificação do conjunto de instituições, faz-se necessária a utilização de critérios tanto mais objetivos possíveis.

Entretanto, para o estudo a que nos propomos, cabe o esforço de interpretação da atividade de pesquisa, uma vez que aí se localiza a questão de interesse. Buscam-se, ainda, elementos relativamente detalhados que sirvam como meio para futuras pesquisas que considerem a especificidade dos casos diversificados, procurando significado na inserção sociorregional que possuem.

De acordo com a classificação proposta por Steiner, existem as universidades de pesquisa e doutorado, as de mestrado e as instituiçóes de graduação. As universidades de mais alto padrão são as chamadas Universidades de Pesquisa e Doutorado Diversificadas, "[...] que oferecem pelo menos 25 programas de doutorado em pelo menos seis grandes áreas do conhecimento e formaram pelo menos 150 doutores/ano no período considerado" (STEINER, 2005a, p. 5). A análise do ano de 2003 mostrou que existiam nove instituiçôes nessa condição entre as 36 universidades de pesquisa e doutorado brasileiras.

O trabalho de classificação de Steiner interessa-nos para fins de esclarecimento sobre parâmetros que são utilizados, nacional e internacionalmente, indicando níveis importantes de exigências quanto à ocupação de posição superior por parte das instituiçôes. Trabalha-se com a hipótese de que a investigação empírica abrangendo uma região não 
central do País - como é o caso do Sul, focalizado na primeira fase - tende a apresentar casos de instituiçóes que revelam muito mais aspectos de identidade propriamente regional do que cosmopolita. Cabe verificar se isso ocorre de fato e como ocorre no caso da relação com o desenvolvimento da atividade de pesquisa nas áreas de investigação.

\section{Regional}

Adota-se a compreensão de que a inserção regional não necessariamente limita a produção de conhecimento, sendo a regiáo o ponto de partida e, em muitos aspectos, a maior beneficiária.

No Ensino Superior brasileiro e internacional, documentos de várias fontes classificam instituiçôes de Ensino Superior como regionais. Conforme documento do Banco Mundial (WORLD BANK, 2000), que propóe uma classificação para instituiçóes de Ensino Superior de países em desenvolvimento, Universidades regionais ou provinciais são aquelas que se voltam para um grande número de estudantes, enfatizando o ensino e a formação para o mercado de trabalho. São públicas e/ou privadas, e geograficamente dispersas, oferecendo oportunidades de formação superior aos estudantes sem que necessitem se deslocar de sua origem regional. Oferecem Educação Superior de massa e servem de base para a expansão do sistema.

A Unesco, responsável por importantes documentos sobre Educação Superior, contribui para que se pense a ideia de identidade regional da Educação Superior e de suas instituições por meio da noção de pertinência. Especialmente no documento resultante da Conferência Mundial sobre Ensino Superior (CMES), de 1998 (UNESCO, 1999b), expôe a noção de pertinência do Ensino Superior como um dos elementos fundamentais para pensar tendências ou perspectivas desse nível de ensino para o século XXI.

A pertinência do Ensino Superior deve ser vista essencialmente em função de seu papel e seu lugar na sociedade, de sua missão em matéria de educação, de pesquisa e dos serviços que dela decorrem, assim como de suas ligaçóes com o mundo do trabalho no sentido mais amplo, de suas relaçóes com o Estado e com as fontes de financiamento públicas 
e de sua interaçáa com os outros graus e formas de ensino. (UNESCO, 1999b, p. 123). [...] Ainda, a pertinência do Ensino Superior está ligada muito particularmente, de um lado, a seu papel enquanto sistema e ao papel de cada uma das instituiçóes que o compóem frente à sociedade, e, de outro, ao que a sociedade dele espera. (UNESCO, 1999a, p. 197).

A noção de pertinência expóe o fato de que a Educação Superior necessita ser válida do ponto de vista da prática sociocultural. Esta envolve desde o utilitário mundo do trabalho, passando pela democratização social e cultural, até chegar a responder a necessidades de desenvolvimento social e humano de longo prazo. Essa noção se relaciona também à validade da Educação Superior presente em diferentes aspectos da realidade social e humana, criando saídas conjuntas para questóes consideradas problemas em caráter local, regional ou mais amplas. A pertinência do Ensino Superior contribui para uma ação de caráter público e para o reconhecimento, pela sociedade, do Ensino Superior e das instituiçóes. Portanto, é cabível pensar em termos de instituições que tenham importante inserção regional, que sejam pertinentes para essas regióes, pesquisando e produzindo conhecimento relevante para responder a essas demandas.

De qualquer forma, as universidades existem no interior de sociedades, e, por conta disso, mesmo as instituições de classe internacional precisam "ter firmes raízes aonde existem", atender a temas e questóes próprios dos seus locais de origem, a fim de melhor funcionar como ponte entre culturas e sociedade (SCHWARTZMAN, 2004).

De um lado, a caracterização de inserção regional não significa necessariamente provincianismo ou paroquialismo. De outro lado, e considerando estudos sociológicos sobre a origem de instituiçóes comunitárias no Rio Grande do Sul, vê-se que, em certas situaçóes, instituiçôes comunitárias e regionais também aparecem associadas à ideia de provincianismo ou paroquialismo, especialmente no período histórico de seu surgimento.

No estudo de Oliven (1990), que focaliza especialmente a situação da classe média e a expansão do Ensino Superior no período posterior à Reforma Universitária de 1968, a autora afirma que 
[...] um dos traços mais notáveis da evolução do sistema de Ensino Superior brasileiro, até a metade da década de 70, foi a sua expansão através da multiplicação de escolas isoladas, mantidas por instituiçóes particulares. Além dos processos de expansão e de privatização, o sistema de Ensino Superior brasileiro, principalmente nas décadas de 60 e 70, assumiu um caráter provinciano, ou seja, se interiorizou através da multiplicação de faculdades isoladas em várias cidades de porte médio. (OLIVEN, 1990, p. 80).

Historicamente, trata-se de um processo de interiorização do Ensino Superior (NEVES, 1995) que ocorreu basicamente a partir da iniciativa de grupos locais e que foi capaz de manter filhos de elites e/ou classe média em seus locais de origem. Assim, esse fenômeno de regionalização veio associado à disposição de comunidades de responderem às suas necessidades de formação superior, o que coloca restrições do ponto de vista da abrangência ou da capacidade de estabelecimento de trocas mais amplas, pelo menos no período inicial. Esse fato caracterizaria o caráter provinciano e é denominado por Oliven (1990) de "paroquialismo".

Salienta-se que, para o presente estudo, a ideia de "regional" ou "pertinente a uma região" é vista como mais promissora do que a ideia de "paroquial". No atual momento histórico, tratando-se de instituiçóes com trajetória histórica e com produção de resultados vinculados ao desenvolvimento, trabalha-se com a hipótese de que tenham obtido um importante avanço em termos de vida acadêmica e de produção de resultados vinculados à região.

Abaixo, o Quadro 1 permite a visualização de elementos de referência na composição das ideias de instituição universitária cosmopolita e regional, para fins da pesquisa em desenvolvimento. Estabeleceram-se como critérios para recortes os seguintes elementos: traços institucionais, como origem e organizaçáo; presença de áreas do conhecimento; identidade e repercussão do trabalho acadêmico; produção resultante da atividade de pesquisa; características do corpo de docentes pesquisadores; público atendido; e repercussão social do conhecimento produzido pela atividade de pesquisa. 


\begin{tabular}{|c|c|c|}
\hline \multicolumn{3}{|c|}{$\begin{array}{l}\text { TIPOS-IDEAIS DE UNIVERSIDADES QUANTO À ABRANGÊNCIA DA } \\
\text { ATIVIDADE DE PESQUISA }\end{array}$} \\
\hline & \begin{tabular}{|l|} 
IDEIA DE INSTITUIÇÃO \\
COSMOPOLITA
\end{tabular} & $\begin{array}{l}\text { IDEIA DE INSTITUIÇÃO } \\
\text { REGIONAL }\end{array}$ \\
\hline $\begin{array}{l}\text { Traços } \\
\text { institucionais }\end{array}$ & $\begin{array}{l}\text { Originada a partir de processos } \\
\text { históricos que envolveram } \\
\text { projetos e açóes comprometidos } \\
\text { com o desenvolvimento nacional } \\
\text { e com disputas internacionais. } \\
\text { - Organizada internamente } \\
\text { com base em colegiados que } \\
\text { disputam óticas acadêmicas. } \\
\text { - Detém importante autonomia } \\
\text { entre mantida e mantenedora. }\end{array}$ & $\begin{array}{l}\text { - Originada a partir da iniciativa } \\
\text { de elites locais, visando ao } \\
\text { desenvolvimento regional. } \\
\text { - Possui colegiados internos } \\
\text { formados por representantes } \\
\text { locais e sem intensos embates } \\
\text { acadêmicos. } \\
\text { - Vínculos de relativa } \\
\text { dependência da mantida em } \\
\text { relaçâo à mantenedora. }\end{array}$ \\
\hline $\begin{array}{l}\text { Áreas do } \\
\text { conhecimento }\end{array}$ & $\begin{array}{l}\text { - Importante diversidade de áreas } \\
\text { com tendência à universalidade. } \\
\text { - Privilegia aprofundamento do } \\
\text { trabalho disciplinar. }\end{array}$ & $\begin{array}{l}\text { - Diversidade de áreas é restrita. } \\
\text { - Valorizaçáo do trabalho multi } \\
\text { e interdisciplinar como recurso } \\
\text { para o fortalecimento da } \\
\text { atividade de pesquisa. }\end{array}$ \\
\hline $\begin{array}{l}\text { Identidade e } \\
\text { repercussáo } \\
\text { acadêmica }\end{array}$ & $\begin{array}{l}\text { - Instituição de pesquisa e que } \\
\text { oferta doutorados reconhecidos } \\
\text { no meio acadêmico } \\
\text { internacional. } \\
\text { - Pesquisa empírica e teórica para } \\
\text { criaçấo teórica. }\end{array}$ & $\begin{array}{l}\text { - Instituiçáo de graduaçáo e } \\
\text { pós-graduaçáo com lato sensu e } \\
\text { certo nível de desenvolvimento } \\
\text { do stricto sensu. } \\
\text { - Pesquisa empírica e teórica } \\
\text { com ênfase na resoluçáo de } \\
\text { problemas. }\end{array}$ \\
\hline $\begin{array}{l}\text { Características } \\
\text { da atividade } \\
\text { de pesquisa }\end{array}$ & $\begin{array}{l}\text { - Competitividade nacional e } \\
\text { internacional. } \\
\text { - Pesquisa com vistas à produçáo } \\
\text { de conhecimento e de teoria de } \\
\text { fronteira. } \\
\text { - Voltada para o desenvolvimento } \\
\text { de tecnologias de ponta em } \\
\text { algumas áreas. } \\
\end{array}$ & $\begin{array}{l}\text { - Competitividade regional e } \\
\text { nacional. } \\
\text { - Produção de conhecimentos } \\
\text { de aplicaçáa relativamente } \\
\text { imediata. } \\
\text { - Pesquisa aplicada. } \\
\text { - Vínculo forte com o } \\
\text { desenvolvimento regional. } \\
\end{array}$ \\
\hline $\begin{array}{l}\text { Produçáo } \\
\text { resultante da } \\
\text { atividade de } \\
\text { pesquisa }\end{array}$ & $\begin{array}{l}\text { - Produção intelectual intensa } \\
\text { em meios de divulgaçáo ou } \\
\text { comunicação científica. } \\
\text { - Orientada para a geração } \\
\text { de produtos acadêmicos de } \\
\text { competitividade internacional } \\
\text { (patentes, processos e produtos). }\end{array}$ & $\begin{array}{l}\text { - Produção intelectual que tem } \\
\text { por base elaboraçóes teórico- } \\
\text { empíricas. } \\
\text { - Geração de processos e produtos } \\
\text { para resolução de problemas } \\
\text { (locais, regionais, de ensino). }\end{array}$ \\
\hline
\end{tabular}

Continua 
Continuação

\begin{tabular}{|c|c|c|}
\hline $\begin{array}{l}\text { Corpo de } \\
\text { docentes } \\
\text { pesquisadores }\end{array}$ & $\begin{array}{l}\text { - Titulação acadêmica alta. } \\
\text { - Titulação com origem } \\
\text { institucional nacional e } \\
\text { internacional. } \\
\text { - Currículos revelam vasta } \\
\text { produção acadêmica e vasta } \\
\text { experiência. } \\
\text { - Dispóe de significativa carga } \\
\text { horária para a atividade de } \\
\text { pesquisa. }\end{array}$ & $\begin{array}{l}\text { - Titulação acadêmica em } \\
\text { crescimento. } \\
\text { - Titulação com origem } \\
\text { institucional regional e } \\
\text { nacional. } \\
\text { - Possui currículos que revelam } \\
\text { relativa experiência e relativa } \\
\text { produção. } \\
\text { - Possui precária carga horária } \\
\text { dedicada à pesquisa. }\end{array}$ \\
\hline $\begin{array}{l}\text { Público } \\
\text { atendido }\end{array}$ & $\begin{array}{l}\text { - Origens geográficas } \\
\text { diversificadas. } \\
\text { - Portadores de alto capital } \\
\text { cultural em suas áreas. }\end{array}$ & $\begin{array}{l}\text { - Origem geográfica localizada } \\
\text { na regiáo. } \\
\text { - Portadores de condiçóes } \\
\text { socioeconômicas variadas e de } \\
\text { relativo capital cultural para a } \\
\text { academia. }\end{array}$ \\
\hline $\begin{array}{l}\text { Repercussáo / } \\
\text { aplicabilidade } \\
\text { social do } \\
\text { conhecimento } \\
\text { produzido } \\
\text { pela atividade } \\
\text { de pesquisa }\end{array}$ & $\begin{array}{l}\text { - Formação de elites e dirigentes } \\
\text { nacionais. } \\
\text { - Repercussão em médio e longo } \\
\text { prazos. } \\
\text { - Produz evidências em setores e } \\
\text { locais diversificados e com os } \\
\text { quais possui relações diretas ou } \\
\text { indiretas. }\end{array}$ & $\begin{array}{l}\text { - Formação de elites locais e } \\
\text { regionais. } \\
\text { - Repercussão em curto e médio } \\
\text { prazos. } \\
\text { - Produz evidências locais e } \\
\text { regionais em setores e locais } \\
\text { com os quais possui relação } \\
\text { mais direta. }\end{array}$ \\
\hline
\end{tabular}

Quadro 1: Tipos-ideais de universidades quanto à abrangência da atividade de pesquisa

Fonte: Elaborado pela autora (2008).

Como foi estabelecido, o recurso ao tipo ideal não tem a pretensão de classificar quanto a modelos hierarquicamente superiores e inferiores. Trata-se de encaminhar possibilidades de interpretação da realidade por meio de dois elementos básicos: (1) a valorização de traços da cultura institucional, de suas práticas e da organização acadêmica daí decorrente e (2) o desenvolvimento da atividade de pesquisa em áreas eleitas, bem como da produção oriunda dessa atividade. Com base nesses elementos, analisam-se aspectos da diversidade encontrada na realidade e sua relação com os tipos referência.

A pesquisa em andamento, que toma como base as noções apresentadas, em sua primeira fase elegeu as áreas de Educação, Direito e Design como focos para busca de dados e informaçóes sobre a atividade de pesquisa. A 
escolha justifica-se tendo em vista a procura significativa de estudantes por cursos oriundos dessas áreas. Dessa forma, ao invés de privilegiar as tradicionais ciências duras ou disciplinarmente mais estabelecidas, optouse por focalizar o campo das Ciências Humanas e Sociais aplicadas. Vale registrar que, historicamente, características dessas áreas ou subáreas eleitas não têm apresentado destaque pela competitividade internacional. Pela própria natureza, áreas como Física e Biologia estão muito mais inseridas em disputas internacionais.

A partir dessa realidade parcial, que focaliza um segmento restrito em termos de áreas de conhecimento e com base na delimitação de estudo em IES da regiấo metropolitana e do interior, com origens e desenvolvimentos próprios, trabalha-se com a hipótese de que instituiçóes com importante identidade regional têm se dedicado a um tipo de produção em pesquisa bastante comprometida em debater e atuar sobre problemas locais/regionais, mas também têm obtido importante grau de repercussão em termos de aprimoramento acadêmico com pares no cenário nacional e, em certa medida, internacionalmente.

$\mathrm{Na}$ realidade de um sistema nacional de Ensino Superior tão heterogêneo quanto o brasileiro, é razoável adotar a ideia de que há espaço para afirmação da diversidade, de modo a contribuir para o avanço do sistema como um todo. Tanto os estudos de Steiner (2005a, 2005b) como o de Schwartzman (2006) mostram limites, tendências e possibilidades existentes no sistema.

Se uma universidade deve ser cosmopolita pela sua própria natureza de trabalho com o saber universal, por outro lado, o desafio da competitividade coloca poucas dessas na possibilidade de atingir o ideal de uma universidade de classe internacional. Ora, entre essa condição e as probabilidades de respostas concretas que as instituiçóes universitárias podem dar às demandas da sociedade, por meio do desenvolvimento da atividade de pesquisa em diversas áreas, há um vasto espaço para ação e para estudos a fim de reconhecer a realidade em suas nuanças e complexidades.

Concretamente, mesmo uma universidade de inserção regional pode ter sua produção originada em problemáticas locais, mas voltadas para debates mais amplos, dialogando com pares localizados em diversos ambientes acadêmicos. De fato, tem se verificado a ampliação do acesso à pós-graduação stricto sensu por meio da ampliação da oferta de cursos 
e programas, e esse fenômeno se verifica na evidência de que a atividade de pesquisa nas universidades também tem amadurecido. Sabe-se, desde o Parecer Sucupira, que ela é condição para o desenvolvimento do stricto sensu, e tem-se um órgão de credenciamento e avaliação que atua com alto rigor - a Coordenação de Aperfeiçoamento de Pessoal de Nível Superior (Capes). Portanto, além das instituições surgidas nas primeiras fases da implantação do sistema de instituições particulares, verifica-se, no presente, o aprofundamento das atividades acadêmicas de várias delas, por meio do que se constata a oferta de pós-graduação em sentido estrito.

A pesquisa que move a presente construção de tipologias tem como foco atual a realidade do Sul do País, uma vez que tanto no Rio Grande do Sul como em Santa Catarina há importante presença de instituições com inserção regional combinada com a origem nas próprias comunidades.

Considera-se o valor de estudos que se ocupam das diferentes regióes do País, entretanto, as condiçóes atuais permitem um estudo restrito, tendo em vista o processo trabalhoso de coleta de dados e as consequentes análises qualitativas e quantitativas que devem servir como base para, no futuro, haver a replicação do método para outros espaços geográficos. Em vários locais do País, há instituiçóes com cursos de pós-graduação recém-reconhecidos pela Capes, por exemplo. Essa situação indica que diferenças importantes entre instituições tendem a ser facilmente evidenciadas.

Por outro lado, as instituições de caráter comunitário e regional são presentes e com atuação crescente. Cabe verificar como esse fenômeno repercute na atividade de pesquisa, na produção de conhecimentos e na sua disseminação, tendo em vista os traços identitários das instituiçóes, a abrangência de sua atuação e as perspectivas de interlocução com outros meios acadêmicos e com a sociedade.

\section{Notas}

1 A pesquisa Traços identitários de instituiçôes do Ensino Superior e a atividade de pesquisa, desenvolvida no período de 2006/2008, contou com apoio da Fundação de Amparo à Pesquisa do Estado do Rio Grande do Sul (Fapergs). O grupo de pesquisa que sediou a investigação - Grupo Interdisciplinar de Estudos sobre Educação Superior/Centro Universitário Ritter dos Reis (GIEES/UniRitter) -, entre outros, trabalhou com 
banco de dados sobre grupos de pesquisa do Diretório dos Grupos de Pesquisa no Brasil/Conselho Nacional de Desenvolvimento Científico e Tecnológico (DGP/CNPq), e com a Plataforma Lattes, em parceria com Programa de Pós-Graduação em Comunicação e Informação/ Universidade Federal do Rio Grande do Sul (PPGCOM/ UFRGS), o qual teve apoio do CNPq pra a investigação.

2 O período de investigação é 1995-2005, uma vez que neste período o segmento do Ensino Superior se transformou de maneira importante, conforme mostram os dados Ministério da Educação/Instituto Nacional de Estudos e Pesquisas Educacionais Anísio Teixeira (MEC/INEP).

3 Apenas entre 1970 e 1975, o setor cresceu 208,3\% (ALMEIDA, 2002, p. 144).

4 A Lei de Diretrizes e Bases da Educação - LDB - no 9.394/96 exige um terço do corpo docente com título de mestre ou doutor, um terço com regime de trabalho em tempo integral e "produção intelectual institucionalizada”, conforme Brasil (2001, p. 33, art. 52, incisos I-III).

5 Steiner (2005a) classifica as instituições quanto à formação acadêmica máxima em Universidades de Pesquisa e Doutorado, de Mestrado e de Graduação. Quanto à diversidade e número de concluintes, classifica-as como Diversificadas, Intermediárias, Restritas e Especializadas. Finalmente, quanto à natureza administrativa, como Públicas, Comunitárias/ Confessionais/Filantrópicas e Particulares.

6 "Não poucas vezes ocorre pequena diferenciação entre os tipos de instituiçóes universitárias. Isso pode ser empiricamente constatado comparando-se, por exemplo, dados quanto à oferta de cursos, ao perfil do alunado, aos resultados de processos avaliativos. Na prática, tal similaridade faz com que ocorra uma competição por recursos entre IES classificadas em categorias diferentes" (NUNES, 2007, p. 20).

7 Tem por base especialmente a Carnegie Foundation, que formulou a primeira classificação para a realidade estadunidense no ano de 1971 e, depois, em 1976, 1987, 1994 e 2000, chegando à classificação do ano de 2005. Distingue Universidades de Pesquisa e Doutorado Extensiva ( 50 doutores ou mais por ano em pelo menos 15 programas); Pesquisa e Doutorado Intensivas (dez doutores ou mais por ano em pelo menos 
três programas, ou 20 doutores ou mais por ano no total); Universidade de Mestrado I (40 mestres ou mais por ano em pelo menos três programas); Universidades de Mestrado II (20 mestres ou mais por ano); Colleges de Bacharelado com programas de graduação, bacharelado de quatro anos; Associate Colleges (bacharelado ao doutorado) e instituiçóes especializadas em ensino de bacharelado ao doutorado, mas em apenas um campo do conhecimento.

\section{REFERÊNCIAS}

ALMEIDA, Paulo Henrique de. A expansão recente do Ensino Superior privado no Brasil e na Bahia. Bahia Análise \& Dados. Salvador, v. 12, n. 3, p. 143-157, dez. 2002.

ALTBACH, Phillip G. The costs and benefits of World-Class

Universities. International Higher Education, Boston, n. 33, p. 5-8, sept./ nov. 2003. Disponível em: <http://www.bc.edu./bc_org/avp/soe/cihe/ newsletter/News33/text003.htm>. Acesso em: 3 ago. 2009.

BRASIL. Câmara dos Deputados. Centro de Documentação e Informação. $L D B$ diretrizes e bases da educação nacional: Lei no 9.394, de 1996, que estabelece as diretrizes e bases da Educação Nacional. 2. ed. Brasília, 2001.

. Lei 5.540, de 28 de novembro de 1968. Fixa normas de organização e funcionamento do Ensino Superior e sua articulação com a escola média, e dá outras providências. In: JusBrasil: legislação. [S.l.], 2010. Disponível em: <http://www.jusbrasil.com.br>. Acesso em: 24 nov. 2009.

CAREGNATO, Célia E. Caráter público e identidade acadêmica na Educação Superior: uma análise da diversificação institucional por meio do estudo de centros universitários. 297f. 2004. Tese (Doutorado em Educação) - Faculdade de Educação, Programa de Pós-Graduação em Educação, Universidade Federal do Rio Grande do Sul, Porto Alegre.

HOLANDA, Aurélio Buarque de et al. Dicionário Aurélio. 3. ed. Curitiba: Positivo, n. 1, 2004. CD-ROM.

NEVES, Clarissa E. B. Ensino Superior privado no Rio Grande do Sul: a experiência das universidades comunitárias. São Paulo: Núcleo de 
Pesquisas sobre Ensino Superior da Universidade de São Paulo, 1995. Documento de Trabalho Nupes 6/95.

NUNES, Edson. Desafio estratégico da politica pública: o Ensino Superior brasileiro. Rio de Janeiro, 2007. Documento de Trabalho Observatório Universitário, 70.

OLIVEN, Arabela C. A paroquialização do Ensino Superior: classe média e sistema educacional no Brasil. Petrópolis: Vozes, 1990.

SAMPAIO, H. Ensino Superior no Brasil: o setor privado. São Paulo: Hucitec; Fapesp, 2000.

SCHWARTZMAN, Simon. A Universidade de São Paulo e a questão universitária no Brasil. In: UNIVERSIDADE DE SÃO PAULO. Instituto de Estudos do Trabalho e Sociedade, 2004. Disponível em: <http://www.iea.usp.br/iea/observatorios/educacao/superior/ historiamissao/schwartzmanauspeaquestaouniversitaria.pdf $>$. Acesso em: fev. 2007.

- A universidade primeira do Brasil: entre intelligentsia: padrão internacional e inclusão social. Estudos Avançados, São Paulo, v. 20, n. 56, p.161-189, jan./abr. 2006.

STEINER, João E. Qualidade e diversidade institucional na pósgraduação brasileira. Estudos Avançados, São Paulo, v. 19, n. 54, p. 341365, ago. 2005a.

. Diferenciação e classificação das instituiçôes de Ensino Superior no Brasil. In: UNIVERSIDADE DE SÃO PAULO. Instituto de Estudos Avançados. São Paulo, 2005b. Disponível em: <http:/usp.br/iea/ ensinosuperior>. Acesso em: fev. 2007.

UNESCO. Politica de mudança e desenvolvimento no Ensino Superior. Rio de Janeiro: Garamond: Unesco/MEC/SESU, 1999a.

. Tendências da Educação Superior para o século XXI. In:

CONFERENCIA MUNDIALSOBRE O ENSINO SUPERIOR: as novas dinâmicas do Ensino Superior e Pesquisas para a Mudança e o Desenvolvimento Social, 1998, Paris. Anais... Brasília: Unesco/CRUB, 1999b. 
WORLD BANK. Constructing Knowledge Societies: new challenges for tertiary education. Washington, D. C., 2003. Disponível em: <www. worldbank.org>. Acesso em: 6 nov. 2007.

. The task force on higher educacion and society: higher educacion in developing countries: peril and promise. Washington, DC, 2000. 


\section{Diversity and differentiation through university research}

\section{Abstract}

National systems of higher education are diversified and complex, which creates conditions for the production of research and knowledge that have varying degrees of repercussion. This article presents the construction of a form of analyzing the relationship between institutional diversity and research activity. Upon finding distinctive characteristics among institutions of the same nature, the paper contributes to knowledge of the higher education system. It uses the Weberian method of analysis of ideal-type, without, however, proposing models for classifying the real institutions, or the ideal models to be achieved.

Key words: Educational research. Higher education. Universities and colleges.
Diversidad y diferenciación a partir de la investigación universitaria

\section{Resumen}

Los sistemas educacionales de enseñanza superior son diversificados y complejos, lo que crea condiciones para la producción de la investigación y del conocimiento por las instituciones con diferentes grados de alcance y repercusión. El presente artículo registra la construcción de un camino para el análisis de la relación entre la diversidad institucional y la actividad de investigación. Al interpretarse la diferenciación de las características de las instituciones de una misma naturaleza, se esta contribuyendo para el conocimiento del sistema de enseńanza superior. Se utiliza la metodología de análisis webweriana de tipo-ideal, sin, por eso proponer modelos para clasificar instituciones reales o modelos ideales a ser alcanzados.

Palabras clave: Investigación educacional. Enseñanza superior. Universidad $\mathrm{y}$ facultades.

\section{Célia Elizabete Caregnato}

Av. Paulo da Gama, 110, Prédio 12.201/ Faced/DEC

Centro - Porto Alegre-RS

CEP: 90046-900

E-mail: celia.caregnato@gmail.com

Recebido em: 11/9/2009

Aprovado em: 3/2/2010 